\title{
A importância do mapeamento das redes de conhecimento para a gestão da informação e do conhecimento em ambientes esportivos: um estudo de caso no Marília Atlético Clube
}

\section{Carlos Francisco Bitencourt Jorge}

Doutorando em Ciência da Informação pela Universidade Estadual Paulista (Unesp/Marília). Mestre em Ciência da Informação pela Universidade Estadual Paulista (Unesp/Marília). Especialista em Administração de Marketing e Propaganda pela Universidade Estadual de Londrina (UEL)

Marta Lígia Pomim Valentim
Pós-Doutorado pela Universidad de Salamanca, Espanha. Livre Docente em Informação, Conhecimento e Inteligência Organizacional pela Unesp. Doutora em Ciências da Comunicação pela Escola de Comunicações e Artes da Universidade de São Paulo (ECA/USP. Mestre pela PUC- Campinas. Docente de graduação e pós- graduação da Universidade Estadual Paulista (Unesp/Marília).

http://dx.doi.org/10.1590/1981-5344/2533

A construção de redes de conhecimento possibilita melhor aproveitamento para o processo de Gestão da Informação (GI) e Gestão do Conhecimento (GC). É importante considerar o mapeamento de fontes informacionais e de fluxos de informação, como base estruturante para a GI e GC. O mapeamento das redes de conhecimento em ambientes com pouca percepção no que tange a importância da informação e do conhecimento, possibilita demonstrar aos sujeitos organizacionais a importância da informação e do conhecimento para o desempenho de processos, atividades e tarefas. Os clubes de futebol não possuem uma cultura voltada à valorização e uso da informação e do conhecimento de modo estruturado. Nessa perspectiva, destacar a importância dos indivíduos nos processos de GI e GC em clubes de futebol, propicia disponibilizar, por meio de um sociograma, as relações 
existentes, bem como as fontes chave para a efetividade da GI e GC. A pesquisa foi realizada no Marília Atlético Clube (MAC), Clube de futebol interior do estado de São Paulo. Identificou-se que, as informações estão centralizadas em poucos indivíduos conforme demonstra o sociograma. A situação complexa evidencia que os indivíduos atuam por tempo determinado no Clube, influindo no comprometimento com os processos de gestão desenvolvidos no clube.

Palavras-Chave: Redes de conhecimento; Gestão da informação; Gestão do conhecimento; Clubes de futebol; Marília Atlético Clube.

\section{The importance of mapping knowledge networks for information management and knowledge in sports environment: a case study in Marilia Athletic Club}

The construction of networking knowledge enables the best use for the process of Information Management (IM) and Knowledge Management (KM). It is important to consider the mapping of informational sources and information flows, a solid basis for the IM and KM. The mapping of networking knowledge in low perception with respect the importance of information and knowledge, enables demonstrate to organizational individuals the importance of information and knowledge for the performance of processes, activities and tasks. The soccer clubs do not have a culture of valuing and use of information and knowledge structured mode. From this perspective, emphasize the importance of individuals in GI and GC processes in soccer clubs, propitiates available through a Sociogram, the relationships and the key sources for the effectiveness of IM and KM. The research was carried in Marilia Athletic Club (MAC), Club Soccer of Marilia City, Sao Paulo State, Brazil. It was identified that the information is centralized in a few people as demonstrated by the Sociogram. The complex situation evidence that individuals act for a specified time at the Club, influencing the commitment management processes developed in the club. 


\section{Keywords: Knowledge networks; Information management; Knowledge management; Soccer clubs; Marilia Athletic Club.}

Recebido em 09.09.2015 Aceito em 29.01.2016

\section{Introdução}

Ao realizarem seus processos, atividades e tarefas as organizações interagem de maneira plena com dados, informações e conhecimentos, uma vez que estes são inerentes a todos os processos. No ambiente interno à organização, bem como no mercado em que atua, a informação é um elemento que pode fazer a diferença em diferentes situações, entretanto, muitas vezes o sujeito organizacional não percebe seu valor.

A informação é essencial para o estabelecimento de diferenciais competitivos, para a mudança da cultura organizacional, entre outras situações. Segundo Moraes e Fadel (2007, p.103), as informações "[...] apoiam o processo decisório, exercem influencias sobre o comportamento das pessoas e passa a ser um vetor importantíssimo, pois podem multiplicar a sinergia dos esforços ou anular o resultado obtido pelo conjunto".

Nessa perspectiva, as organizações devem usufruir ao máximo suas redes de conhecimento que, se relacionam de maneira direta com a Gestão da Informação e do Conhecimento. É fundamental a percepção da importância das redes para um melhor aproveitamento das informações e conhecimentos gerados no ambiente interno e externo, auxiliando os processos de tomada de decisão, de modo a obter mais produtividade, qualidade e, consequentemente, mais competividade, gerando inteligência competitiva (IC) para a organização (CAVALCANTE; VALENTIM, 2008).

Assim, evidencia-se a importância do mapeamento das redes de conhecimento para a GI e GC nas organizações esportivas, mais especificamente os clubes de futebol. Questiona-se se os clubes de futebol, mais precisamente o Marília Atlético Clube, constituem redes de conhecimento, bem como qual o impacto das redes de conhecimento para a GI e GC.

Dessa maneira, debater sobre as questões que envolvem a informação, as fontes de informação, os fluxos de informação e suas relações com a GI e a GC, e aspectos que envolvem a cultura organizacional, visando demonstrar como é constituída as redes de conhecimento do Clube. 


\section{0 impacto da informação e do conhecimento em ambientes esportivos}

Mattelart (2002) e Choo (2003) destacam que quase todos os processos organizacionais são alicerçados por informação, ou seja, os processos utilizam de maneira direta ou indireta uma gama de informações que, em sua maioria, são transformadas em conhecimento.

Destaca-se que a informação faz parte do contexto organizacional, cujo objetivo é propiciar aos sujeitos organizacionais o uso eficiente dos recursos existentes internos, bem como os advindos externamente a ela. As informações estão contidas em diferentes suportes e mídias e nos próprios indivíduos.

A informação esportiva é conceituada por Clarke, Aquesolo e Niquet (2000 ${ }^{1}$ apud MONTEIRO; BOTELHO, 2009, p. 58) como:

[...] informação especializada, que diz respeito ao domínio específico das atividades físicas desportivas e do lazer, e que os usuários dos serviços estão cada vez mais exigentes com relação à eficácia do serviço e à boa adequação dos produtos de informação às suas necessidades.

A informação esportiva após sua seleção, análise e organização pode assumir papel estratégico, principalmente, para a construção de conhecimento. A necessidade de informação esportiva está totalmente relacionada ao ambiente ao qual ela é gerada, bem como às necessidades do usuário desse segmento.

Ressalta-se que existe um número ilimitado de informações informais no ambiente externo, trafegando em fluxos informais, que podem se transformar em informações formais na interação com os sujeitos organizacionais. Estes, por sua vez, são capazes de transformálas em conhecimento. Além disso, de acordo com as necessidades/demandas dos usuários, as informações de distintas fontes e ambientes podem se inter-relacionar transformando-se em novos dados informações, fator determinante para a geração de conhecimento.

No contexto esportivo, é possível mapear de maneira mais eficiente as informações deste nicho, uma vez que cada esporte conta com sua própria gama de informações especializadas.

CLARKE, N.; AQUESOLO, J. A.; NIQUET, J.-P. Manual do centro de informação desportiva. [S.I.]: Comité Olímpico Internacional, 2000. 
Figura 1 - Informação formal e informal na transformação de nova informação - conhecimento

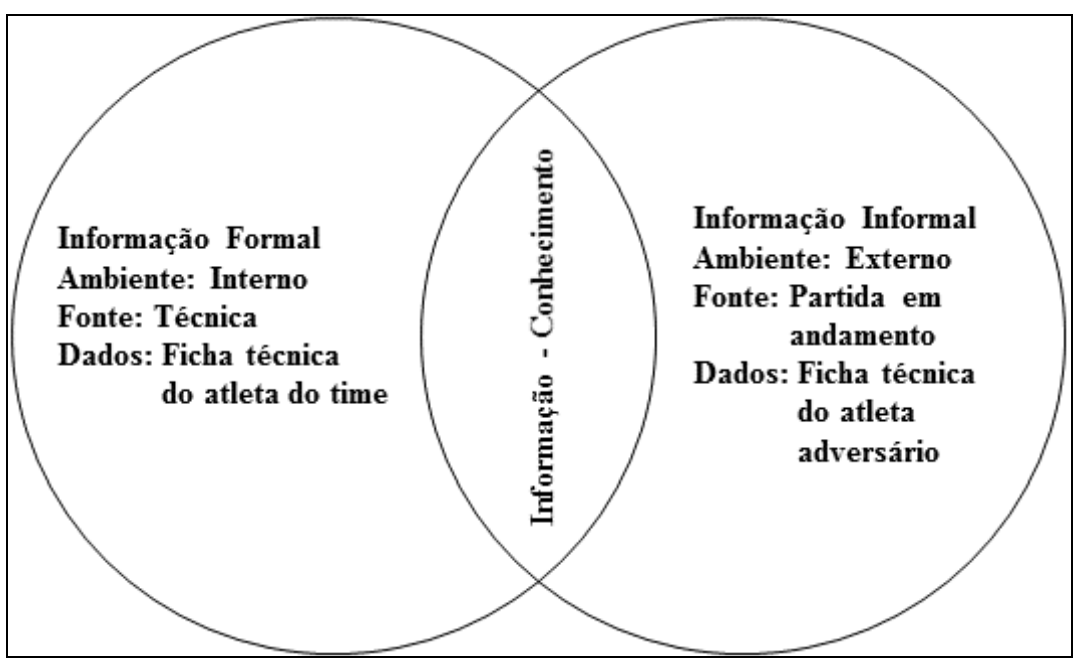

Fonte: Elaboração própria.

A informação esportiva pode ser delimitada sob dois vieses. O primeiro: as informações registradas em algum tipo de suporte, como livros, relatórios, periódicos, entre outros. O segundo: as informações não registradas, ou seja, informações que não possuem registros formalizados em um determinado suporte em virtude da dinamicidade do ambiente e do esporte ou, até mesmo, pela ausência de percepção dos indivíduos quanto ao valor da informação.

A informação esportiva relacionada ao futebol deve ser direcionada às necessidades e demandas de seu público: informações situacionais sobre o jogo, visando escolher a melhor opção tática; histórico do atleta; dados estatísticos relativos às partidas anteriormente realizadas etc. Sendo assim, há a junção da informação formal, que possui uma fonte da área técnica do ambiente interno, cujas informações estruturadas (formais), podem ser transformadas em conhecimento, a partir da percepção e apropriação por um determinado sujeito cognoscente. Isso possibilita a geração de conhecimento individual que pode ser compartilhado posteriormente (fluxos informais) (Figura 1).

Davenport e Harris (2007) mencionam que o uso de informação e conhecimento de maneira estratégica é uma prática realizada por esportes como o beisebol, o futebol, o basquete, entre outros. No âmbito técnico, a estatística é frequentemente utilizada no basquete e no beisebol gerando dados e informações que visam à melhoria contínua do esporte, cujo êxito ocorre devido ao alinhamento das informações à percepção e à criatividade de quem faz uso das informações.

O técnico do St. Louis Cardinals, Tony La Russa (cujo time venceu o World Series em 2006), um dos melhores treinadores de beisebol, combina de forma brilhante a inteligência analítica e a intuição para 
Clube

decidir quando contratar uma personalidade contagiante para alavancar o moral da equipe (DAVENPORT; HARRIS, 2007, p. 22).

O futebol americano utiliza a informação e conhecimento no esporte como por exemplo o New England Patriots, que emprega as informações quase de maneira plena, abordando a área administrativa, técnica e mercadológica, analisando a satisfação dos torcedores. Um dos esportes mais lucrativos do mundo é o futebol americano. A informação nesse contexto propicia o apoio à tomada de decisão resultando na construção de conhecimento desde o nível técnico até a área administrativa, proporcionando êxito em competições esportivas.

O New England Patriots, por exemplo, tem demonstrado um desempenho particularmente bem-sucedido, com a vitória recente de três Super Bowls ${ }^{2}$ em quatro anos. O time faz uso extensivo de dados e modelos analíticos, tanto em campo quanto fora dele. Profundas análises ajudaram o time a selecionar seus jogadores e ainda permanecer abaixo do teto salarial (no ano passado, a média salarial do time ficou no vigésimo quarto lugar na National Football League ${ }^{3}$ ). 0 time seleciona jogadores sem utilizar os serviços de olheiros empregados por outros times e classifica as seleções potenciais com base em fatores não tradicionais, como inteligência e disposição de usar o ego pessoal em benefício da equipe (DAVENPORT; HARRIS, 2007, p. 22-23).

A utilização da informação no âmbito técnico também faz parte da maneira com que a equipe do New England Patriots trabalha, demonstrando que o uso de informação para gerar conhecimento é fundamental para projetar situações e antever as estratégias dos adversários.

[...] fazem a utilização extensiva da inteligência analítica para decisões em campo. Eles empregam estatísticas para decidir se tentam fazer um ou dois pontos depois de um touchdown ou se desafiam a decisão do juiz, por exemplo. Tanto seus técnicos quanto os jogadores são reconhecidos por seu

2 Super Bowl é um jogo do campeonato da National Football League (NFL) estadunidense que decide o campeão da temporada do ano anterior. Disputada desde 1967, a partir da junção das duas principais ligas do desporto no país (NFC e AFC), é o maior evento desportivo e a maior audiência televisiva do país, assistido anualmente por milhões de pessoas nos Estados Unidos e em todo o mundo. É também um evento que apresenta a publicidade mais cara da televisão, pois patrocinadores desembolsam pequenas fortunas para exibirem suas propagandas no intervalo. Disponível em: <http://pt.wikipedia.org/wiki/Super_Bowl>. Acesso em: 22 jul. 2012.

${ }^{3}$ A National Football League (NFL) é a maior liga de futebol americano do mundo, com trinta e dois times nos Estados Unidos. Em termos de renda e número de fãs, a NFL é a maior liga de esportes na América do Norte. O valor médio dos clubes avaliado em 2008 é de 1,04 bilhão de dólares, sendo o mais valioso o Dallas Cowboys, que chega a valer 1,612 bilhão de dólares. A divisão mais valiosa da NFL é a NFC Leste, formada por Cowboys, Washington Redskins, New York Giants e Philadelphia Eagles, todos valendo mais de um bilhão de dólares. Disponível em: <http://pt.wikipedia.org/wiki/National_Football_League>. Acesso em: 22 jul. 2012. 
extensivo estudo de filmagem de jogos e estatística, e o treinador chefe, Bill Belichick, é famoso por ler compenetradamente artigos de economistas acadêmicos sobre probabilidades estatísticas de resultado do futebol americano (DAVENPORT; HARRIS, 2007, p. 23).

O uso da informação como insumo para situações mercadológicas é evidenciado, quando a equipe utiliza os resultados obtidos para melhoria constante do negócio esportivo. Assim, se compreende de modo mais amplo o principal cliente que é o torcedor, possibilitando a realização de mudanças estratégicas, usando como base a opinião dos próprios clientes.

Fora de campo, o time utiliza análises detalhadas para avaliar e melhorar a "experiência total dos fãs". Em cada jogo em casa, por exemplo, entre 20 e 35 pessoas recebem a tarefa específica de criar indicadores quantitativos para a comida, 0 estacionamento, o pessoal, a limpeza dos banheiros, entre outros fatores. Os fornecedores externos de serviços são monitorados, para renovação de contratos e recebem incentivos para melhorar seu desempenho (DAVENPORT; HARRIS, 2007, p. 23).

Uma organização esportiva ou o ambiente esportivo possui informações financeiras, de mercado, entre outras, obviamente possuindo particularidades decorrentes do contexto. Sendo assim, e tendo o esporte futebol como delimitador, observa-se que a informação esportiva ganha uma nova subdivisão, a 'informação futebolística'. Segundo Simões (2009), o futebol tem como objetivo central a realização do gol durante o jogo, assim, vencer a partida, fazendo mais gols que o adversário é o objetivo da equipe.

No âmbito do futebol, observa-se vários atores que se relacionam entre si, bem como entre as instituições em que atuam. Como exemplo, pode-se mencionar o jogador que no nível informacional pode ser tratado de maneira individual (o atleta em si), entretanto, também pode ser tratado de maneira coletiva (representa e defende um clube de futebol).

Para vencer seu adversário, um time deve obter com presteza mais informações que seu rival. Deve saber escolher, entre as alternativas que possui, suas probabilidades e agir com 0 máximo de velocidade. O termo probabilidade refere-se, também, à teoria da informação. O jogo de futebol caracteriza-se pela maior ou menor escolha de alternativas que cada jogador é capaz de obter por meio da informação. Compare-se a atuação de uma equipe altamente qualificada com outra com baixo teor de técnica, velocidade, motivação (SIMÕES, 2009, p. 26). 
Nesse sentido, torna-se importante a compreensão das informações e de seus múltiplos contextos dentro de um clube de futebol, pois uma informação para um determinado sujeito pode não ter relevância, e para outro indivíduo a mesma informação pode trazer oportunidades. Em todos os níveis e contextos a informação esportiva alimenta o processo de tomada de decisão e a geração de novos conhecimentos, proporcionando maior assertividade para esta atividade, concedendo vantagem competitiva na sua aplicação.

\section{Fontes e fluxos informacionais na construção de redes de conhecimento e suas relações com a gestão da informação e a gestão do conhecimento}

Com o mapeamento das fontes de informação e de conhecimento e dos fluxos formais e informais é possível analisar as relações e conexões entre as fontes e fluxos e, assim, construir uma rede de conhecimento capaz de evidenciar o comportamento informacional em um determinado ambiente. Tomaél (2008) destaca a importância dos atores, bem como o mapeamento das informações e fluxos para a rede de conhecimento.

A principal ação para mobilizar uma rede de conhecimento está relacionada ao movimento da informação na rede. Impulsionar e incentivar o compartilhamento da informação e a construção do conhecimento na rede é condição sine qua non para sua sustentação e crescimento. Os atores incumbidos dessa tarefa ou que se dispuserem a exercer o papel de estimular a partilha na rede deverão contar com a confiança dos membros da rede. (TOMAÉL, 2008, p. 12).

Para que uma rede de conhecimento seja constituída é necessário mapear e monitorar os fluxos informacionais e as fontes do ambiente em que a rede se encontra. Outro ponto importante é entender a relação entre a rede do conhecimento e os processos de Gestão da Informação (GI) e de Gestão do Conhecimento (GC). Assim, compreender a importância dos fluxos informacionais para a GI e GC, torna-se fundamental, nessa perspectiva, é necessário conceituar o principal insumo do fluxo informacional, qual seja, a informação.

Segundo Valentim (2008, p.18), a informação é "[...] ao mesmo tempo, objeto e fenômeno, visto que pode ser destacada e analisada por si mesma e, também, pode ser parte de um processo". Ao conceituar o termo 'informação', é importante delimitar outros dois componentes que, se relacionam, interagem e sofrem transformações na relação com a informação: 'dado' e 'conhecimento'. Davenport e Prusak (1998), Valentim (2002) e Pérez-Montoro (2004) conceituaram dado, informação e conhecimento à luz da gestão da informação. 
Os autores compreendem 'dados' como simples observações sobre o estado do mundo, ou seja, são dados registrados com o auxílio de algum suporte; na maioria das vezes, com o auxílio de tecnologias. No que tange a 'informação' é compreendida como dotada de relevância e propósito; em outras palavras, pode-se afirmar que são dados com atribuição de significado e contextualizados por um indivíduo. Conhecimento é compreendido como um elemento que reside na mente humana, construído na relação do indivíduo com o mundo.

Sendo assim, parte-se do pressuposto que a informação está presente em todas as atividades organizacionais, conforme evidencia Choo (2003, p. 27):

A informação é um componente intrínseco de quase tudo que uma organização faz. Sem uma compreensão dos processos organizacionais pelos quais a informação se transforma em percepção, conhecimento e ação, as empresas não são capazes de perceber a importância de suas fontes e tecnologias de informação.

A informação é considerada um componente intrínseco às atividades organizacionais e, por essa razão, torna-se importante identificar seu comportamento no ambiente organizacional em que está inserida.

Os fluxos informacionais se constituem no meio para que a informação possa trafegar entre o emissor e o receptor da informação e, para tal, precisa ser comunicada ou compartilhada. Valentim (2010, p. 13) reforça esta dependência e relação entre informação e fluxos:

Os fluxos de informação ou fluxos informacionais se constituem em elemento fundamental dos ambientes informacionais, de tal forma que não há ambiente informacional sem haver fluxos de informação e vice-versa. Os fluxos informacionais são reflexos naturais dos ambientes ao qual pertencem, tanto em relação ao conteúdo quanto em relação à forma.

Valentim (2002) relaciona os fluxos informacionais a três níveis organizacionais, estrutura física (organograma), estrutura de recursos humanos (capital intelectual) e estrutura informacional (dados, informação e conhecimento). A autora ao realizar um paralelo entre os fluxos informacionais e os níveis organizacionais destaca dois tipos de fluxos, os fluxos formais e os informais (Figura 2).

Evidencia-se que, é por meio das inter-relações entre os sujeitos organizacionais que os fluxos são constituídos. Os fluxos informais atuam diretamente com os conhecimentos gerados pelos sujeitos organizacionais, e estes perpassam todos os níveis organizacionais, operacional, tático e estratégico. Os fluxos informais trabalham com 
recursos intangíveis no ambiente organizacional, qual seja, o conhecimento. A dificuldade de torná-lo tangível é um desafio, bem como alinhar a falta de percepção dos sujeitos organizacionais quanto à importância deste recurso se constituem em fator complicador para seu pleno aproveitamento.

Figura 2 - Ambientes organizacionais

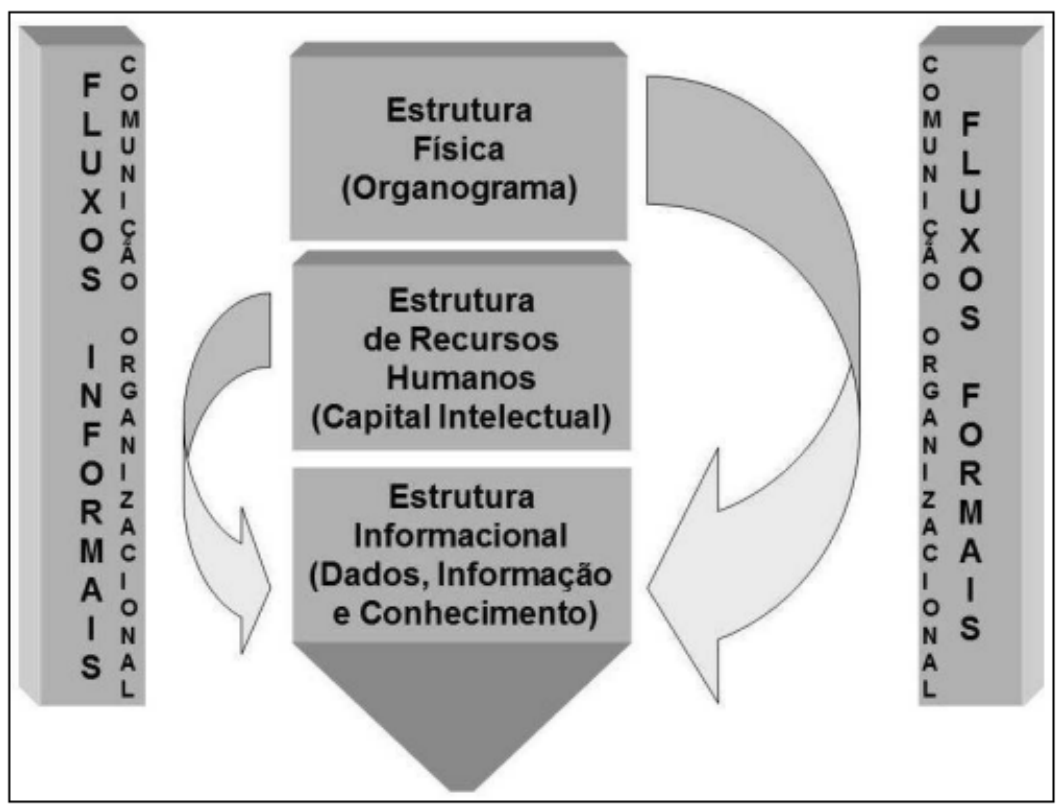

Fonte: VALENTIM (2006, p. 14).

Para que a organização possa usufruir plenamente os elementos que circulam nos fluxos formais e informais é necessário a implementação de uma cultura organizacional voltada à valorização da informação e do conhecimento. Nessa perspectiva, a gestão do conhecimento atua fornecendo estratégias para converter o conhecimento tácito em conhecimento explícito e a gestão da informação atua fornecendo estratégias para converter dados em informação relevante.

Davenport e Prusak (1998, p. 27) destacam quatro abordagens relacionadas às fontes e fluxos informacionais:

1 informação não estruturada;

2 capital intelectual ou conhecimento;

3 informação estruturada em papel;

4 informação estruturada em computadores.

Segundo os autores supracitados (DAVENPORT; PRUSAK, 1998), a informação não estruturada é a forma mais antiga de informação. Tratase de informações que dependem de profissionais especializados, que devem ter proximidade com as informações, com os usuários e suas necessidades. Davenport e Prusak (1998, p. 29) explicam que as informações não estruturadas se constituem em elementos comuns nas 
organizações descentralizadas, "Algumas informações não-estruturadas rumores, fofocas, histórias - continuarão não estruturadas. É assim que as coisas acontecem em organizações cada vez mais descentralizadas".

Para estes autores (DAVENPORT; PRUSAK, 1998, p. 30) o capital intelectual ou conhecimento é o resultado do relacionamento entre a informação e o indivíduo e ressaltam a dificuldade em adquirir esse tipo de informação, pois "o conhecimento muitas vezes é um processo longo e confuso, e as maneiras de utilizá-lo são múltiplas e imprevisíveis. Quase todas as primeiras tentativas de 'construir' o conhecimento falharam".

Os mesmos autores evidenciam que a informação não estruturada e o capital intelectual são insumos para a GC. Enquanto os fluxos informais trabalham diretamente com o conhecimento e as informações não estruturadas, os fluxos formais trabalham com o conhecimento explícito, ou seja, as informações que estão contidas em algum tipo de suporte. Valentim (2008) conceitua gestão do conhecimento destacando a importância dos indivíduos no processo de GC, bem como a relação do processo com a gestão da informação.

A gestão do conhecimento é um conjunto de atividades que visa trabalhar a cultura organizacional/informacional e a comunicação organizacional/informacional em ambientes organizacionais, no intuito de propiciar um ambiente positivo em relação criação/ geração, aquisição/apreensão, compartilhamento/socialização e uso/utilização de conhecimento, bem como mapear os fluxos informais (redes) existentes nesses espaços, com o objetivo de formalizá-los, na medida do possível, a fim de transformar o conhecimento gerado pelos indivíduos (tácitos) em informação (explícito), de modo a subsidiar a geração de ideias, a solução de problemas e o processo decisório em âmbito organizacional (VALENTIM, 2008, p. 4).

Observa-se que, enquanto para a GC as fontes são as pessoas, para a GI as fontes estão dispersas em distintos nichos e em diferentes suportes e mídias responsáveis por registrar e armazenar tal conteúdo. As informações registradas em papel dominaram o contexto informacional até o início da Década de 70 do Século XX. Davenport e Prusak (1998) as classificam como informações estruturadas e, segundo estes autores, com o aumento do volume de informações, intensificou-se, igualmente, a complexidade, o que torna impraticável "Uma abordagem centralizada, altamente planejada, é insustentável para essa vasta quantidade de informação. Até os arquivos mais bem cuidados não terão nenhum valor se não forem utilizados" (DAVENPORT; PRUSAK, 1998, p. 33).

Os processos de identificação das necessidades informacionais dos sujeitos organizacionais, a aquisição, o armazenamento, o tratamento, a organização, a disseminação e 0 uso efetivo da informação são relacionados a modelos, ferramentas de gestão e tecnologias, que são aplicadas para a realização das atividades organizacionais. 
Nessa perspectiva, é necessário compreender, alinhar e, em muitos casos, realizar mudanças no que tange à cultura da organização, fator que interfere diretamente no comportamento informacional dos sujeitos organizacionais. Desse modo, somente com a junção desses elementos é possível realizar a GI e a GC de maneira plena.

Evidencia-se que a GI não se reduz simplesmente a aplicação de tecnologias de informação. Cabe a GI atuar no processo gerenciando as variáveis relacionadas aos fluxos de informações. Monteiro e Valentim (2008, p. 56) explicam que os fluxos formais podem ocorrer,

[...] de forma horizontal, transversal e vertical. Os fluxos informacionais horizontais são constituídos por diferentes unidades organizacionais do mesmo nível hierárquico, os fluxos informacionais transversais ocorrem por meio de diferentes unidades organizacionais de diferentes níveis hierárquicos e os fluxos informacionais verticais são construídos por meio de diferentes níveis hierárquicos de uma mesma área organizacional. Ressalta-se que os fluxos ocorrem por meio de interações formalizadas e sistematizadas no ambiente organizacional.

Dessa maneira, tanto os fluxos formais quanto os fluxos informais estão presentes nas atividades de GI e GC, principalmente, quando ocorre os processos de apropriação e compartilhamento. A identificação, mapeamento e monitoramento das fontes e fluxos tornam-se essenciais para que ocorra o melhor aproveitamento desses modelos de gestão.

\section{Materiais e métodos}

Aplicou-se o método 'Estudo de Caso' que, segundo Yin (2001, p. 21), "[...] contribui, de forma inigualável, para a compreensão que temos dos fenômenos individuais, organizacionais, sociais e políticos". Nessa perspectiva, optou-se pela triangulação de dados que consiste na utilização de três técnicas, neste caso, a observação, o questionário e a entrevistas, visando coletar dados e informações em todos os níveis da organização. A triangulação propicia proceder a uma análise aprofundada sobre a problemática pesquisada, obtendo resultados mais consistentes, bem como conferindo maior validade aos dados e análises realizadas.

A pesquisa foi realizada no Marília Atlético Clube (MAC), Clube que disputava a Série B do Campeonato Estadual Paulista. Como sujeitos de pesquisa participaram todos os indivíduos diretamente vinculados ao futebol profissional do MAC. Na base da estrutura do Clube, estão os jogadores e a Comissão Técnica e, assim, analisou-se a percepção destes sujeitos no que tange às fontes de informação e os fluxos formais e informais, por meio da aplicação de um questionário, bem como buscou- 
se mapear as principais fontes e fluxos informacionais [formais e informais] e compreender as relações existentes entre eles.

$\mathrm{Na}$ linha intermediária do Clube, estão os gestores, coordenadores da equipe e a assessoria responsável por realizar a intermediação entre o nível operacional e estratégico do Clube. Ressalta-se que este nível é considerado essencial para uso das fontes e fluxos, afinal, trata-se do nível responsável por inter-relacionar visões e coordenar ações no âmbito do Clube. Desse modo, aplicou-se uma entrevista estruturada, cuja finalidade consistiu na validação e na busca de informações não fornecidas pelas questões contidas nos questionários.

Figura 3 - Sujeitos de pesquisa distribuídos por nível hierárquico

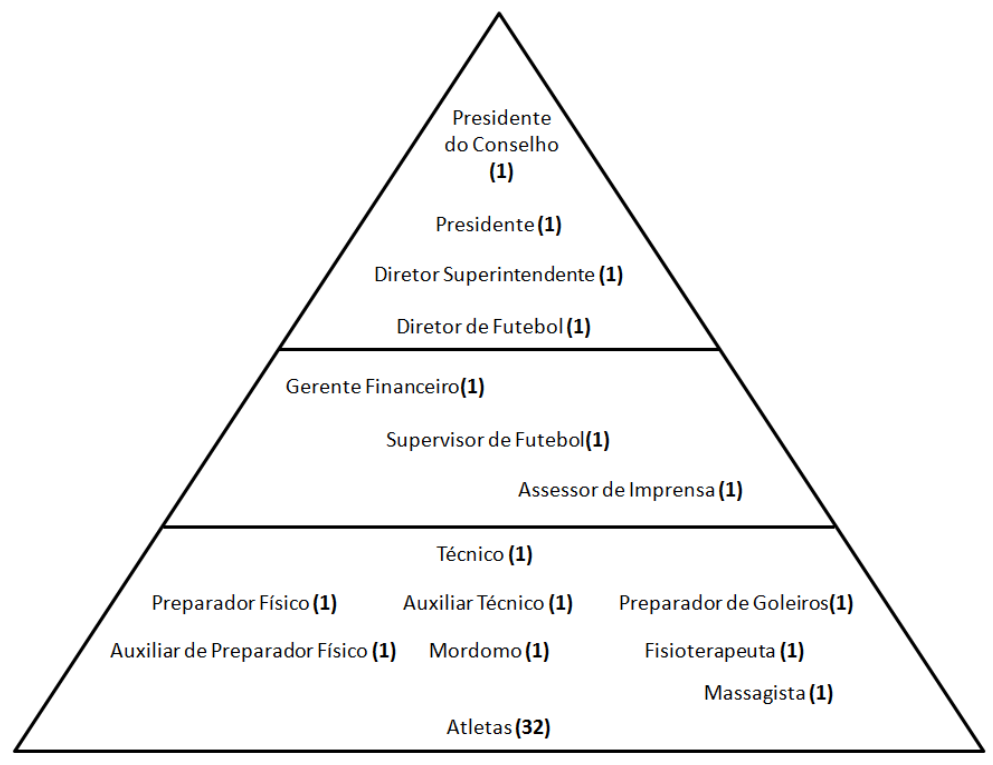

Fonte: Elaboração própria.

No que tange a estratégia do Clube, os diretores são responsáveis por realizar o planejamento de longo prazo, assim, compreender a dinâmica das conexões, fontes e fluxos informacionais deste nível hierárquico foi fundamental. Paralelamente a pesquisa descritivaexploratória, realizou-se uma revisão bibliográfica cuja finalidade foi fundamentar a construção do referencial teórico, bem como estabelecer relações entre a teoria e a realidade observada.

Todos os sujeitos organizacionais que possuem alguma relação com o futebol profissional do MAC participaram da coleta de dados, sendo quatro sujeitos vinculados a Diretoria Executiva, correspondendo a 8,52\% do total; o nível estratégico contou com três sujeitos, ou seja, $6,38 \%$ do total; do nível operacional foram quarenta sujeitos, correspondendo a $85,10 \%$ do total. 


\section{Análise e apresentação dos resultados}

Após mapear os fluxos, bem como as fontes mais acessadas aplicouse o Sociograma, técnica que propicia uma melhor compreensão das relações entre os sujeitos organizacionais de um grupo ou entre grupos. Desse modo, foi possível compreender quais são os indivíduos mais acessados no contexto informacional do Clube, e como é composta a rede de conhecimento.

Verificou-se junto aos sujeitos pesquisados a quem recorrem quando buscam informações nas áreas técnicas e administrativas. Como não havia limitação em relação a quantidade de indicações, alguns indivíduos mencionaram mais de uma pessoa e área. Por outro lado, alguns indivíduos não fizerem indicações sobre suas relações, o que pode demonstrar a falta de compreensão destes quanto ao questionamento ou, ainda, dificuldade de compreensão em relação a informação para o desempenho de suas atividades. Ressalta-se, também, que o termo 'atletas' que consta nas tabelas e gráficos representam os 32 (trinta e dois) jogadores do Clube que foram agrupados para uma melhor visualização dos gráficos.

A divisão entre a área técnica e administrativa foi necessária para que fosse possível entender as relações sob diferentes prismas, afinal, os sujeitos organizacionais pesquisados trabalham em duas grandes áreas, que possuem informações independentes e relacionáveis. Nessa perspectiva, foram desenvolvidas 3 (três) matrizes sociais: Geral, Administrativa e Técnica. Na matriz existe uma diferença em relação a tonalidade de cores das células, que se refere ao nível organizacional em que os sujeitos organizacionais atuam. Sendo assim, as células de tonalidade cinza claro representam os componentes que fazem parte do nível operacional do Clube; cinza médio representam os membros do nível tático; e cinza escuro representam os sujeitos que compõem a Diretoria Executiva do Clube (nível estratégico). Esta diferenciação foi aplicada, visando destacar os distintos níveis e suas relações ao observar a matriz.

A primeira matriz demonstra as relações existentes no Clube de maneira geral, tanto as autorizações no contexto técnico quanto as autorizações no contexto administrativo, conforme é possível observar na Tabela 1 e Gráfico 1. A Tabela 1 destaca a frequência de requisições realizadas ao Treinador e ao Gestor de Futebol, 28 (vinte e oito) e 20 (vinte) respectivamente, realizadas pelos sujeitos organizacionais que compõem o Clube.

Evidencia-se a importância e a confiabilidade que esses sujeitos possuem para os demais membros do Clube. Na sequência encontra-se o Preparador Físico e o Diretor de Futebol, com 17 (dezessete) e 16 (dezesseis) requisições respectivamente, demonstrando que a maioria das informações requisitadas pelas pessoas do Clube estão centralizadas em poucos indivíduos. 


\section{Tabela 1 - Matriz Social do Clube - Contexto Geral}

\begin{tabular}{|c|c|c|c|c|c|c|c|c|c|c|c|c|c|c|c|c|}
\hline $\begin{array}{l}\text { Quem } \\
\text { requer } \\
\text { informaçäo }\end{array}$ & 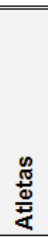 & 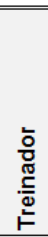 & 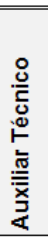 & 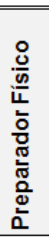 & 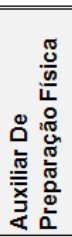 & 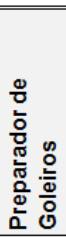 & 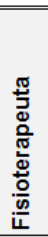 & 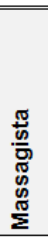 & $\begin{array}{l}\stackrel{\circ}{E} \\
\text { 은 } \\
\text { 일 }\end{array}$ & 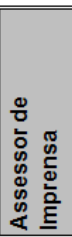 & 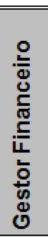 & 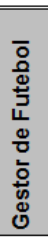 & 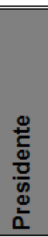 & 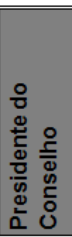 & 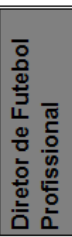 & 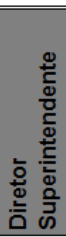 \\
\hline Atletas & & 18 & 2 & 12 & & 2 & & & & & 1 & 10 & & & 15 & \\
\hline \multicolumn{17}{|l|}{ Treinador } \\
\hline Auxiliar Técnico & & 1 & & & & & & & & & & 1 & & & & \\
\hline Preparador Físico & & 1 & & . & & & & & & & & 1 & & & & \\
\hline Auxiliar de Preparação Física & & & & 1 & & & & & & & & 1 & & & & \\
\hline Preparador de Goleiros & & 1 & & 1 & & & & & & & & 1 & & & & \\
\hline Fisioterapeuta & & 1 & & & & & & & & & & 1 & & & & \\
\hline Massagista & & & & 1 & & & & & & & & 1 & & & 1 & 1 \\
\hline Mordomo & & & 1 & 1 & & & & & & & & & & & & \\
\hline Assessor de Imprensa & & 1 & & & & & & & & & & & & & & 1 \\
\hline Gestor Financeiro & & 1 & & & & & & & & & & & & & & \\
\hline \multicolumn{17}{|l|}{ Gestor de Futebol } \\
\hline Presidente & & 1 & & & & & & & & & & 1 & & & & \\
\hline Presidente do Conselho & & 1 & & & & & & & & & & 1 & & & & \\
\hline Diretor de Futebol Profissional & & 1 & & & & & & & & & & 1 & & & & \\
\hline Diretor Superintendente & & 1 & & & & & & & & & & 1 & & & & \\
\hline Total & 0 & 28 & 3 & 17 & 0 & 2 & 0 & 0 & 0 & 1 & 2 & 20 & 0 & 0 & 16 & 2 \\
\hline
\end{tabular}

Fonte: Dados da pesquisa.

\section{Gráfico 1 - Gráfico Social do Clube - Geral}

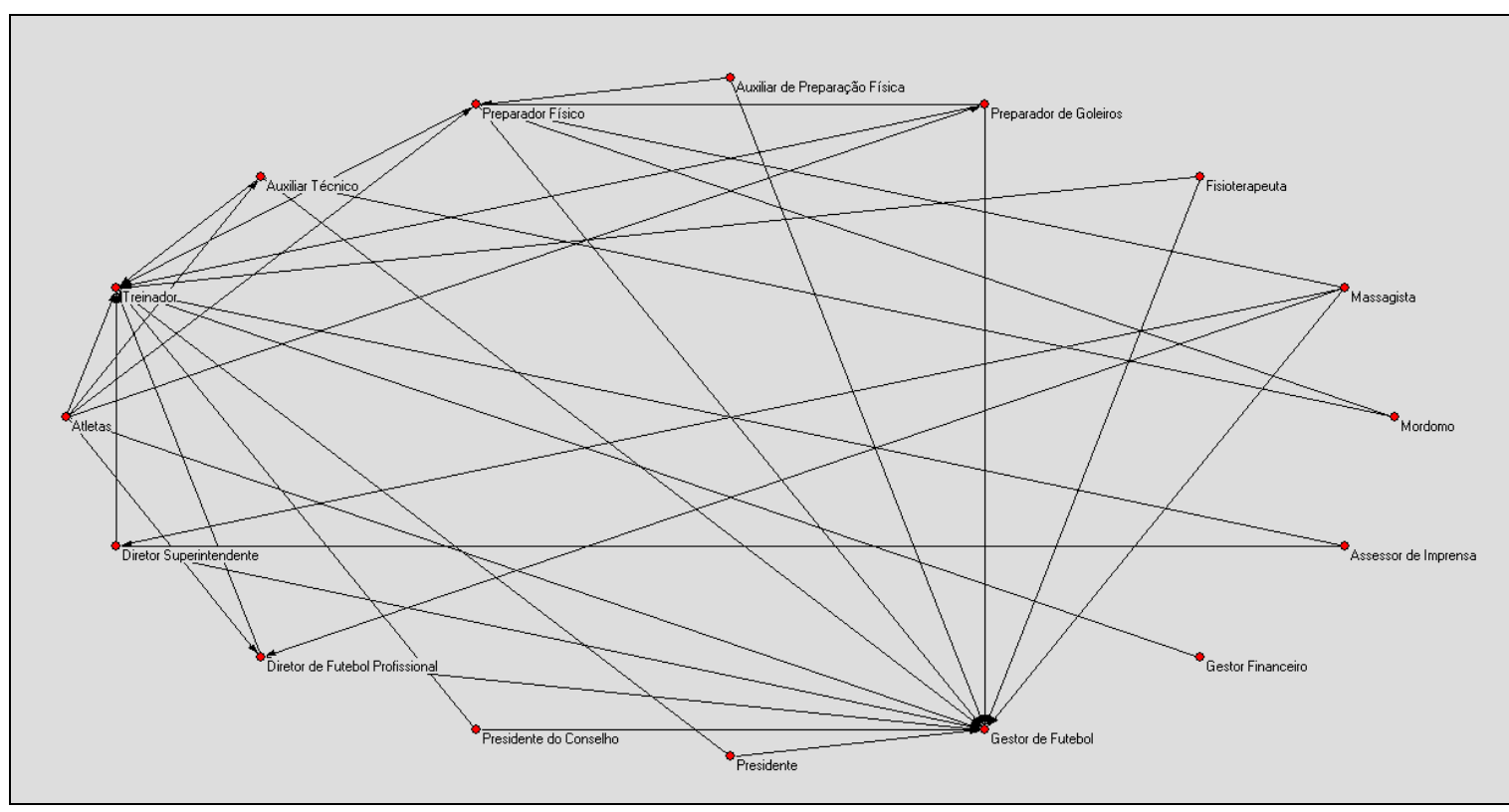

Fonte: Dados da pesquisa.

No contexto geral as informações são acessadas por 4 (quatro) pessoas, sendo que 2 (dois) são do nível operacional, Treinador e Preparador Físico, 1 (um) no nível tático, Gestor de Futebol, e apenas 1 
(um) membro do nível estratégico, Diretor de Futebol do Clube (Gráfico 1).

Tabela 2 - Matriz Social do Clube - Contexto Administrativo

\begin{tabular}{|c|c|c|c|c|c|c|c|c|c|c|c|c|c|c|c|c|}
\hline $\begin{array}{l}\text { Quem } \\
\text { Quencede } \\
\text { informaçäo } \\
\text { requer } \\
\text { informaçäo }\end{array}$ & 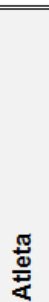 & 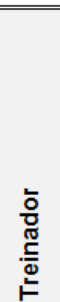 & 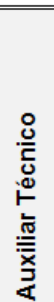 & 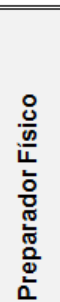 & 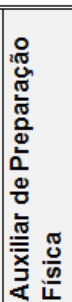 & 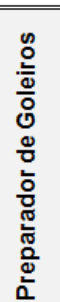 & 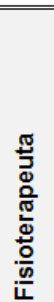 & 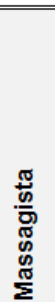 & $\begin{array}{l}\circ \\
\text { 음 } \\
\text { 을 }\end{array}$ & 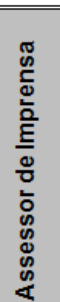 & 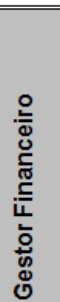 & 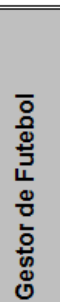 & 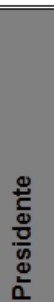 & 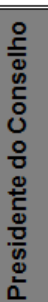 & 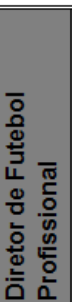 & 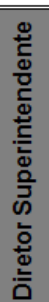 \\
\hline Atletas & & & & & & & & & & & 1 & 10 & & & 15 & \\
\hline \multicolumn{17}{|l|}{ Treinador } \\
\hline Auxiliar Técnico & & & & & & & & & & & & 1 & & & & \\
\hline Preparador Físico & & & & & & & & & & & & 1 & & & & \\
\hline Auxiliar de Preparação Física & & & & & & & & & & & & 1 & & & & \\
\hline Preparador de Goleiros & & & & & & & & & & & & 1 & & & & \\
\hline Fisioterapeuta & & & & & & & & & & & & & & & & 1 \\
\hline Massagista & & & & & & & & & & & & 1 & & & & \\
\hline Mordomo & & & & & & & & & & & & 1 & & & 1 & \\
\hline Assessor de Imprensa & & & & & & & & & & & & 1 & & & & 1 \\
\hline Gestor Financeiro & & & & & & & & & & & & 1 & & & & \\
\hline Gestor de Futebol & & & & & & & & & & & & & & & 1 & 1 \\
\hline Presidente & & & & & & & & & & & & 1 & & & & \\
\hline Presidente do Conselho & & & & & & & & & & & & 1 & & & & \\
\hline Diretor de Futebol Profissional & & & & & & & & & & & & 1 & & & & \\
\hline Diretor Superintendente & & & & & & & & & & 1 & 1 & 1 & & & & \\
\hline Total & 0 & 0 & 0 & 0 & 0 & 0 & 0 & 0 & 0 & 1 & 2 & 21 & 0 & 0 & 16 & 2 \\
\hline
\end{tabular}

Fonte: Dados da pesquisa.

\section{Gráfico 2 - Gráfico Social do Clube - Contexto Administrativo}

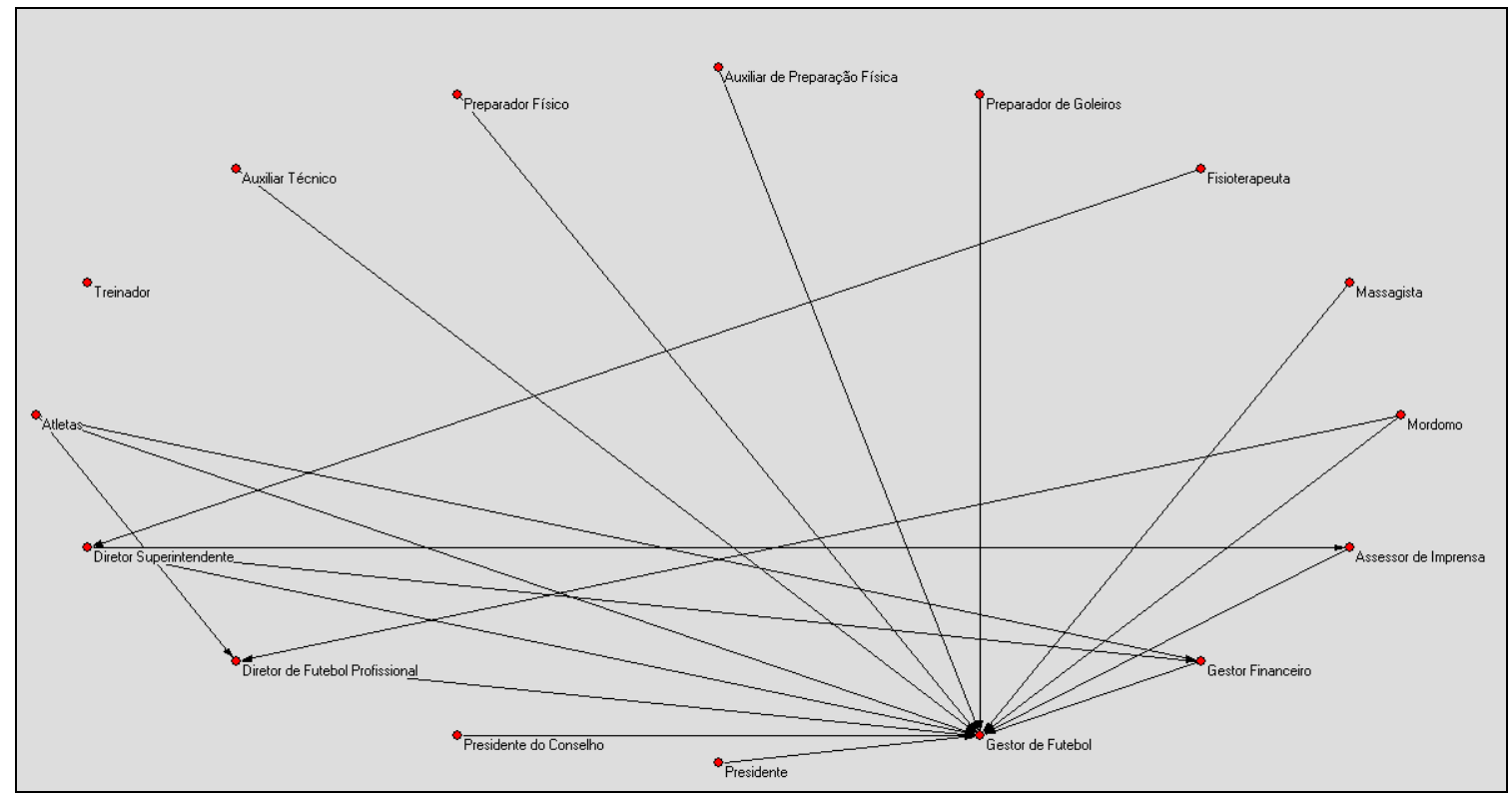

Fonte: Dados da pesquisa. 
A Tabela 2 corresponde ao comportamento dos sujeitos pesquisados quanto a requisição de informações no contexto administrativo do Clube. E possível observar que a frequência de requisição se refere a 2 (dois) indivíduos, o Gestor de Futebol e o Diretor de Futebol, com 21 (vinte e uma) e 16 (dezesseis) requisições respectivamente.

Destaca-se também que 2 (dois) sujeitos foram indicados com 2 (duas) requisições, o Diretor Financeiro e o Gestor Financeiro, e apenas 1 (um) indicou o Assessor de Imprensa. A intensidade de frequência pode ser visualizada no Gráfico 2 do sociograma do Clube no contexto administrativo.

No contexto das informações técnicas evidencia-se o Treinador como sendo o sujeito mais requisitado com 29 (vinte e nove) indicações, seguido do Preparador Físico com 16 (dezesseis) requisições, conforme se observa na Tabela 3. O Gestor de Futebol foi indicado por 2 (dois) sujeitos, mesmo este não estar diretamente relacionado com a estrutura técnica do Clube.

Tabela 3 - Matriz Social do Clube - Contexto Técnico.

\begin{tabular}{|c|c|c|c|c|c|c|c|c|c|c|c|c|c|c|c|c|}
\hline $\begin{array}{l}\text { Quem } \\
\begin{array}{r}\text { Concede } \\
\text { informaçäo }\end{array} \\
\text { requer } \\
\text { informaçäo }\end{array}$ & $\begin{array}{l}\frac{\tilde{J}}{2} \\
\frac{\tilde{\omega}}{4}\end{array}$ & 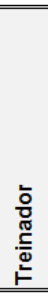 & 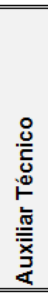 & 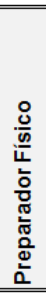 & 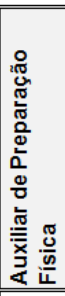 & 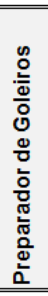 & 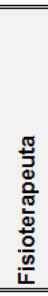 & 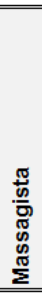 & 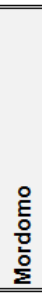 & 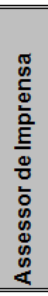 & 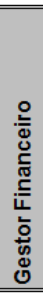 & 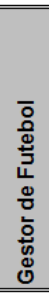 & 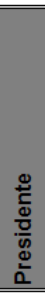 & 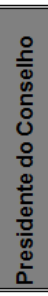 & 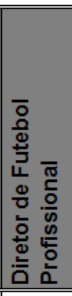 & 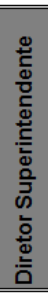 \\
\hline Atletas & & $\overline{119}$ & 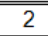 & $\overline{12}$ & & 3 & & & & & & & & & & \\
\hline \multicolumn{17}{|l|}{ Treinador } \\
\hline Auxiliar Técnico & & 1 & & & & & & & & & & & & & & \\
\hline Preparador Físico & & 1 & & 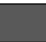 & & & & & & & & & & & & \\
\hline Auxiliar de Preparação Física & & & & 1 & & & & & & & & & & & & \\
\hline Preparador de Goleiros & & 1 & & 1 & & & & & & & & & & & & \\
\hline Fisioterapeuta & & 1 & & & & & & & & & & & & & & \\
\hline Massagista & & & & 1 & & & & & & & & & & & & \\
\hline Mordomo & & & 1 & 1 & & & & & & & & & & & & \\
\hline Assessor de Imprensa & & 1 & & & & & & & & & & & & & & \\
\hline Gestor Financeiro & & 1 & & & & & & & & & & 1 & & & & \\
\hline Gestor de Futebol & & 1 & & & & & & & & & & & & & & \\
\hline Presidente & & 1 & & & & & & & & & & & & & & \\
\hline Presidente do Conselho & & 1 & & & & & & & & & & & & & & \\
\hline Diretor de Futebol Profissional & & 1 & & & & & & & & & & & & & & \\
\hline Diretor Superintendente & & 1 & & & & & & & & & & & & & & \\
\hline Total & 0 & 29 & 3 & 16 & 0 & 3 & 0 & 0 & 0 & 0 & 0 & 2 & 0 & 0 & 0 & \\
\hline
\end{tabular}

Fonte: Dados da pesquisa.

Outros 2 (dois) sujeitos da área técnica foram citados, o Preparador de Goleiros com 3 (três) indicações e o Auxiliar Técnico com o mesmo número de requisições. Destaca-se a presença do Preparador de Goleiros nesta matriz sendo indicado por 3 (três) indivíduos, sendo que os 3 (três) sujeitos atuam como goleiros, demonstrando o vínculo estreito entre os jogadores desta posição com seu treinador direto. 
Clube

Gráfico 3 - Gráfico Social do Clube - Contexto Técnico

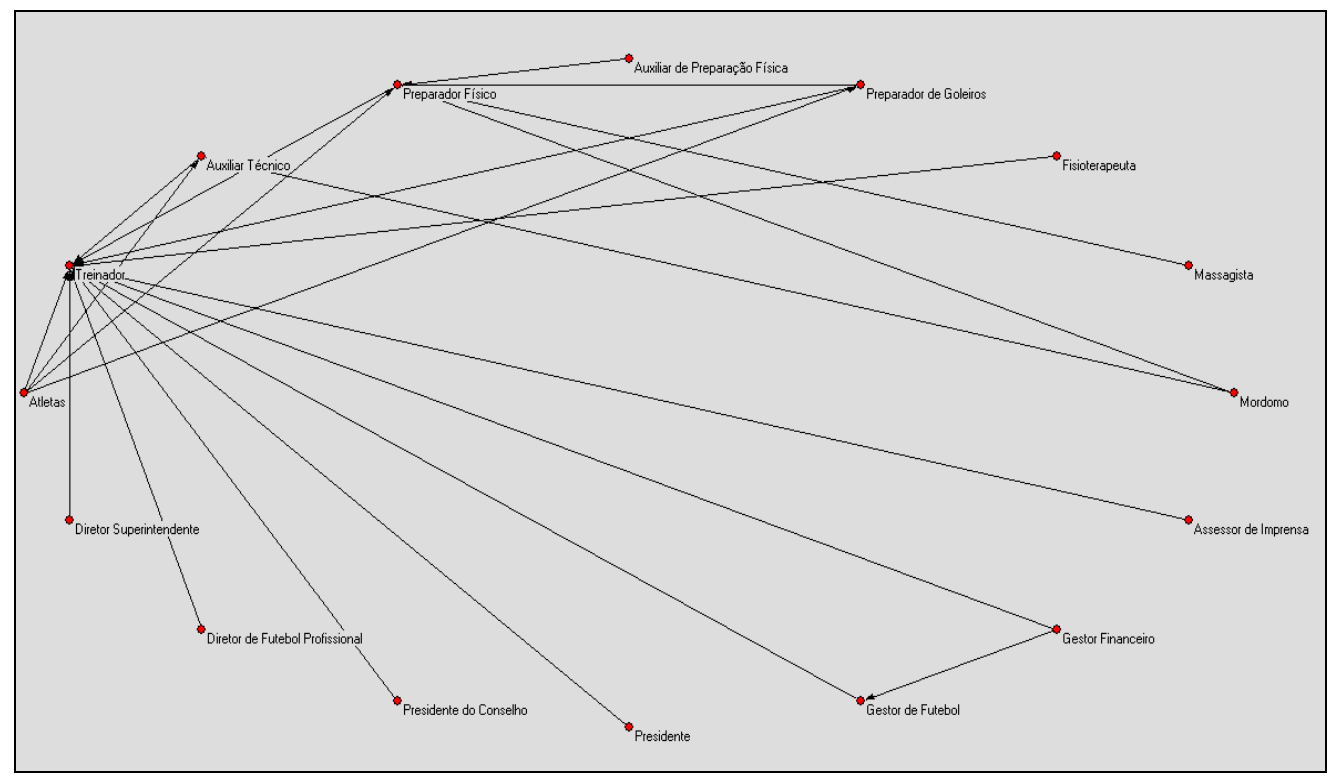

Fonte: Dados da pesquisa.

O Gráfico 3 apresenta a frequência das requisições realizadas entre os membros do contexto técnico do Clube, demonstrando centralidade no Treinador e do Preparador Físico.

\section{Considerações finais}

Por meio do processo de observação alinhada à aplicação de instrumentos de pesquisa foi possível reproduzir por meio de tabelas e gráficos a rede de conhecimento do Marília Atlético Clube (MAC) em três dimensões. Evidenciou-se quais são as fontes informacionais mais acessadas e, consequentemente, identificou-se os fluxos de informações mais relevantes para os sujeitos organizacionais do MAC.

Destaca-se que os sujeitos requisitados pelos membros do Clube no contexto técnico, são indivíduos que desenvolvem atividades por tempo determinado como, por exemplo, o Treinador, que permanece no Clube enquanto traz resultados positivos, quando isso não ocorre ele é dispensado. Outro exemplo ocorre no nível estratégico, mais especificamente no âmbito da Diretoria, uma vez que possuem asseguradas suas funções nas quais são vinculados os cargos que exercem de maneira eletiva, normalmente pelo período de 4 (quatro) anos de acordo com o estatuto do Clube.

Ressalta-se que devido à falta de continuidade nos trabalhos desenvolvidos por esses sujeitos, porquanto os indivíduos que assumem esses cargos impõem seus próprios modelos e métodos e quando há troca dos referidos sujeitos, os modelos e métodos são normalmente descartados e novos modelos e métodos são aplicados pelos indivíduos que passam a ocupar os referidos cargos. 
Tais situações demonstram certa fragilidade e uma possível dificuldade do Clube para a implementação dos processos de GI e GC. Tal fragilidade é evidenciada, mais especificamente no que tange a importância do mapeamento da rede de conhecimento para a realização da gestão da informação e da gestão do conhecimento. Afinal, a rede de conhecimento pode ser considerada a estrutura básica que, propicia a implementação e realização dos processos de GI e GC.

Observa-se que, nos fluxos informacionais do Clube trafegam um número ilimitado de informações. Destaca-se o fluxo informal, pois nele trafegam informações referentes à área técnica, existindo um número significativo de informações que pertencem e fazem parte da área técnica. A maioria se refere a informações que são disseminadas, apropriadas, utilizadas e transformadas em conhecimento. São informações que não estão registradas em algum suporte, ou seja, são conhecimentos, tornando o processo de transmissão e/ou compartilhamento complexo, porquanto o conhecimento esta intrínseco aos indivíduos.

Muitas informações circulam nos fluxos informais devido à dinamicidade do ambiente e a dificuldade de registrá-las. A difícil percepção e compreensão dos indivíduos em relação à importância da informação, e de seu registro para a geração de conhecimento faz com que o Clube se desenvolva de modo mais lento que as organizações de outros segmentos econômicos.

O Clube realiza de maneira não estruturada pequenas atividades que remetem ao processo de GI e GC, contudo, a falta de uma metodologia adequada e estruturada influi no uso e reuso pleno dos insumos gerados no âmbito da rede de conhecimento. Sugere-se como parâmetros um melhor aproveitamento das informações e conhecimentos contido no Clube a adoção de tecnologias de informação e comunicação que propiciem o mapeamento e a centralização das informações relevantes em uma única base de dados.

Assim, o acesso, seleção, análise, organização, armazenamento, gestão e disseminação das informações para uso e reuso em diferentes atividades podem se tornar mais eficientes. Recomenda-se se desenvolver outras pesquisas no âmbito da Ciência da Informação, enfocando esse cenário extremamente complexo, de maneira a aprofundar os estudos de outros elementos que não foram vistos nesta pesquisa.

\section{Referências}

CAVALCANTE, L. F. B.; VALENTIM, M. L. P. Comportamento informacional em ambientes empresariais. In: VALENTIM, M. L. P. (Org.). Gestão da informação e do conhecimento no âmbito da Ciência da Informação. São Paulo: Polis; Cultura Acadêmica, 2008. p. 117-128.

CHOO, C. W. A organização do conhecimento: como as organizações usam a informação para criar significado, construir conhecimento e tomar decisões. São Paulo: SENAC, 2003. 
DAVENPORT, T. H.; HARRIS, J. G. Competição analítica. Rio de Janeiro: Campus, 2007.

DAVENPORT, T. H.; PRUSAK, L. Ecologia da informação: por que só a tecnologia não basta para o sucesso na era da informação. São Paulo: Futura, 1998.

MATTELART, A. História da sociedade da informação. São Paulo: Loyola, 2002.

MONTEIRO, A. M. R. C. da C.; BOTELHO, M. A. G. M. A importância do trabalho com a informação jurídica esportiva na cidade de São Paulo. CRB-8 Digital, São Paulo, v. 2, n. 2, p.55-65, set., 2009. Disponível em: <http://revista.crb8.org.br/index.php/crb8digital/article/viewFile/7/7 > Acesso em: 16 jun. 2012.

MONTEIRO, N. A.; VALENTIM, M. L. P. Necessidades informacionais e aprendizagem no ciclo de vida de um projeto. Revista Digital de Biblioteconomia e Ciência da Informação, Campinas (SP), v. 5, n. 2, p. 53-66, jan./jun. 2008. Disponível em: $<$ http://143.106.108.14/seer/ojs/index.php/rbci/article/view/380/257>. Acesso em: 16 jun. 2012.

MORAES, C. R. B. de; FADEL, B. Ambiência organizacional, gestão da informação e tecnologia. In: VALENTIM, M. L. P. (Org.). Informação, conhecimento e inteligência organizacional. 2. ed. Marília: FUNDEPE Editora, 2007. p. 99-114.

PÉREZ-MONTORO, M. Identificación y representación del conocimiento organizacional: la propuesta epistemológica clásica. [S.I.]: IN3 - Internet Interdisciplinary Institute, 2004. (Documentos de Proyecto, DP04-001). Disponível em: <http://www.uoc.edu/in3/dt/20390/20390.pdf>. Acesso em: 2 fev. 2012.

SIMÕES, R. P. Futebol e informação: driblando incertezas. Porto Alegre: EDIPUCRS, 2009.

TOMAÉL, M. I. Redes de conhecimento. DataGramaZero: Revista de Ciência da Informação, Rio de Janeiro, v.9, n.2, p. 1-14, abr. 2008. Disponível em: <http://www.dgz.org.br/abr08/Art_04.htm>. Acesso em: 14 abr. 2015.

VALENTIM, M. L. P. Inteligência competitiva em organizações: dado, informação e conhecimento. DataGramaZero: Revista de Ciência da Informação, Rio de Janeiro, v.3, n.4, p. 1-13, ago. 2002. Disponível em: <http://www.dgz.org.br/ago02/Art_02.htm>. Acesso em: 16 mar. 2013.

VALENTIM, M. L. P. Processo de inteligência competitiva organizacional. In: VALENTIM, M. L. P. (Org.). Informação, conhecimento e inteligência organizacional. Marília: FUNDEPE Editora, 2006. p. 9-24. 
VALENTIM, M. L. P. Gestão da informação e gestão do conhecimento em ambientes organizacionais: conceitos e compreensões. Tendências da Pesquisa Brasileira em Ciência da Informação, v.1, n.1, p. 1-16, 2008. Disponível em: <http://inseer.ibict.br/ancib/index.php/tpbci/article/view/110/151>. Acesso em: 27 jan. 2009.

VALENTIM, M. L. P. Ambientes e fluxos de informação. In: VALENTIM, M. L. P. (Org.). Ambientes e fluxos de informação. São Paulo: Polis; Cultura Acadêmica, 2010. p. 13-22.

YIN, R. K. Estudo de caso: planejamento e métodos. 2. ed. São Paulo: Bookman, 2003. 